\title{
SOFT COMPUTING PENILAIAN KONDISI PERKERASAN JALAN BERBASIS ARTIFICIAL NEURAL NETWORKS
}

\author{
Dadang Iskandar', Leni Sriharyani ${ }^{2}$ \\ Prodi Teknik Sipil Universitas Muhammadiyah Metro ${ }^{1,2}$ \\ E-mail : dadangummetro@gmail.com ${ }^{1}$, lenisriharyani@yahoo.co.id ${ }^{2}$
}

\begin{abstract}
ABSTRAK
Seiring dengan kemajuan perekonomian yang semakin mantap, pembangunan infrastruktur termasuk pembangunan jalan antar kabupaten/kota menjadi katalisator dalam meningkatkan perekonomian daerah. Demikian halnya dengan Kota Metro Provinsi Lampung, yang menjadi pilihan tempat dilakukannya penelitian ini. Terdapat banyak jalan yang sering mengalami kerusakan dan terjadi secara berulang tanpa penanganan yang tuntas. Untuk mengatasi masalah tersebut perlu dilakukan evaluasi kinerja perkerasan sebelum dilakukan tindakan penanganan agar diperoleh hasil yang optimal. Dalam melakukan penilaian perkerasan terdapat dua metode yaitu dengan cara destruktif dan nondestruktif. Salah satu cara non-destruktif yang umum dikembangkan adalah Pavement Condition Index (PCI), dimana penilaian dilakukan dengan cara yang relatif panjang dan rumit, selain itu dibutuhkan perangkat lunak yang cukup mahal. Untuk itu penelitian ini berupaya mengembangkan metode alternatif sederhana dengan menggunakan teknik optimasi berbasis Artificial Neural Networks (ANN). Untuk tujuan ini jalan sepanjang 15 $\mathrm{km}$ lebih di wilayah studi diperiksa dan hasil perhitungan ANN menunjukkan bahwa kerusakan didominasi alligator crack dan rutting yang memerlukan penanganan lebih serius. Perhitungan yang dilakukan ANN menunjukan bahwa pemeliharaan harus diprioritaskan untuk beberapa section dengan nilai terkecil 66,03. Hasil yang sebanding dengan metode PCI konvensional yaitu 65,70 sehingga dapat disimpulkan bahwa perhitungan lunak ANN dapat menjadi alternatif dalam memprediksi kerusakan jalan dengan prosedur yang lebih sederhana.
\end{abstract}

Kata Kunci : Pavement Condition Index (PCI), Artificial Neural Networks (ANN), kerusakan jalan, non-destruktif.

\section{PENDAHULUAN}

Sistem transportasi yang baik diperlukan dalam perekonomian modern, dan jaringan jalan raya merupakan komponen yang umum dan penting dari sistem tersebut. Sistem jaringan jalan raya memiliki dua tujuan yaitu memungkinkan pergerakan kendaraan penumpang dan pergerakan kendaraan barang dengan kecepatan yang tepat (Kelly, Delaney, Chai, \& Mohamed, 2016). Perkerasan jalan merupakan bagian penting dari infrastruktur transportasi. Perkerasan jalan dibangun untuk menahan beban yang diharapkan sesuai dengan umur rencana. Pentingnya perkerasan untuk transportasi yang aman dan andal serta kebutuhan akan perawatan berkala, oleh karena itu pengkajian kondisi perkerasan menjadi bagian penting dari sistem manajemen perkerasan jalan. Saat ini terdapat beberapa indeks yang digunakan untuk menggambarkan kondisi perkerasan seperti PCI, PSI, IRI, dan PSR. Indeks ini 
memfasilitasi penilaian kondisi perkerasan menjadi indeks praktis (Huang, 2004).

Pembangunan jalan sangat dibutuhkan, karena kondisi jalan raya dapat menghambat dan mengganggu lalu lintas. Kerusakan jalan antara lain disebabkan oleh beberapa faktor, salah satu faktor yang berpengaruh signifikan adalah beban berlebih (Hadiwardoyo, Sumabrata, \& Berawi, 2012). Perkerasan merupakan komponen penting dari sistem transportasi darat. Penting untuk meningkatkan kinerja jalan guna memenuhi kebutuhan masyarakat perkotaan yang terus berkembang. Hal ini dapat dicapai dengan menerapkan strategi pengobatan yang tepat (Shah, Jain, Tiwari, \& Jain, 2013). Model prediksi perkerasan yang andal diperlukan untuk sistem manajemen infrastruktur jalan atau sistem manajemen perkerasan jalan (Meegoda \& Gao, 2014). Evaluasi kinerja perkerasan menggunakan pavement condition index (PCI) yang merupakan komponen dasar dari Pavement Management System (PMS) (Yogesh U. Shah, 2012). PCI adalah indeks numerik yang banyak digunakan untuk mengevaluasi kondisi struktural dan operasional perkerasan jalan. Perkiraan PCI didasarkan pada hasil inspeksi visual dengan mengidentifikasi jenis, tingkat keparahan dan jumlah gangguan (Shahnazari, Tutunchian, Mashayekhi, \& Amini, 2012).

Informasi gangguan perkerasan juga diperoleh melalui survei lapangan yang dilakukan oleh personel terlatih. Pemasangan video untuk mendapatkan gambar visual dilakukan untuk mengotomatiskan perolehan data kerusakan jalan. Selain itu, praktisi juga tertarik untuk memperkirakan kondisi kerusakan jalan di masa depan untuk tujuan alokasi anggaran (Lou, Gunaratne, Lu, \& Dietrich, 2001). Penggunaan ANN pada sistem geomekanis dan perkerasan jalan telah meningkat secara signifikan.
Selain itu, keberhasilan penerapan ilmu pengambilan keputusan dan teknik komputer diharapkan dapat meningkatkan kepercayaan lebih lanjut dalam penerapannya di semua bidang teknik sipil. Penilaian tenaga ahli harus dilakukan secara rutin di bidang transportasi terkait penerapan ANN agar bisa lebih baik lagi (Chen \& Flintsch, 2007). Penelitian sebelumnya dilakukan dengan memasukkan 21 jenis parameter kerusakan dengan tingkat keparahan yang berbeda-beda. Penggunaan ANN dan Genetic Programming (GP) serta mempertimbangkan analisis statistik menunjukkan akurasi yang tinggi dari model yang dikembangkan (Shahnazari et al., 2012).

Selanjutnya pengembangan model ANN yang mampu memprediksi modulus lapisan perkerasan secara cepat dan andal (Leiva-Villacorta, VargasNordcbeck, \& Timm, 2017).

Perhitungan yang rumit dengan langkah-langkah yang panjang dan membutuhkan ketersediaan perangkat lunak dan nomogram menjadi kendala bagi para insinyur untuk menyelesaikan hasil survei lapangan menjadi nilai rediksi PCI. Dalam penelitian ini ANN digunakan untuk memprediksi nilai PCI. Model yang dikembangkan dilatih berdasarkan hasil survei kerusakan pada jalan arteri di Kota Metro Provinsi Lampung, Indonesia. Input model adalah parameter yang merepresentasikan jenis distress, tingkat keparahan, dan volume kerusakan yang dapat menghasilkan prediksi PCI.

\section{METODE PENELITIAN}

Studi parametrik model komputasi lunak dilakukan untuk mengetahui pengaruh input pada PCI. Penelitian ini dilakukan untuk memverifikasi model yang telah disiapkan. Metodologi ini didasarkan pada perubahan parameter masukan tunggal dalam kisaran nilai maksimum dan minimum dengan tetap 
mempertahankan parameter penyisipan lainnya seperti nilai rata-rata.

\section{Lokasi penelitian}

Lokasi penelitian ini berada di jalan arteri di Kota Metro Provinsi Lampung. Perkerasan pada ruas ini dikaji karena merupakan jalan penghubung antara Kabupaten Lampung Timur, Kabupaten Lampung Tengah dan Kota Metro yang ditunjukkan pada gambar 1. Dan diperikirakan ruas jalan ini relatif sering mengalami kerusakan sehingga diharapkan penelitian ini dapat membantu pemerintah daerah dalam menangani kerusakan jalan dengan menampilkan berbagai kerusakan yang dapat diterapkan pada program yang tepat dan efektif.

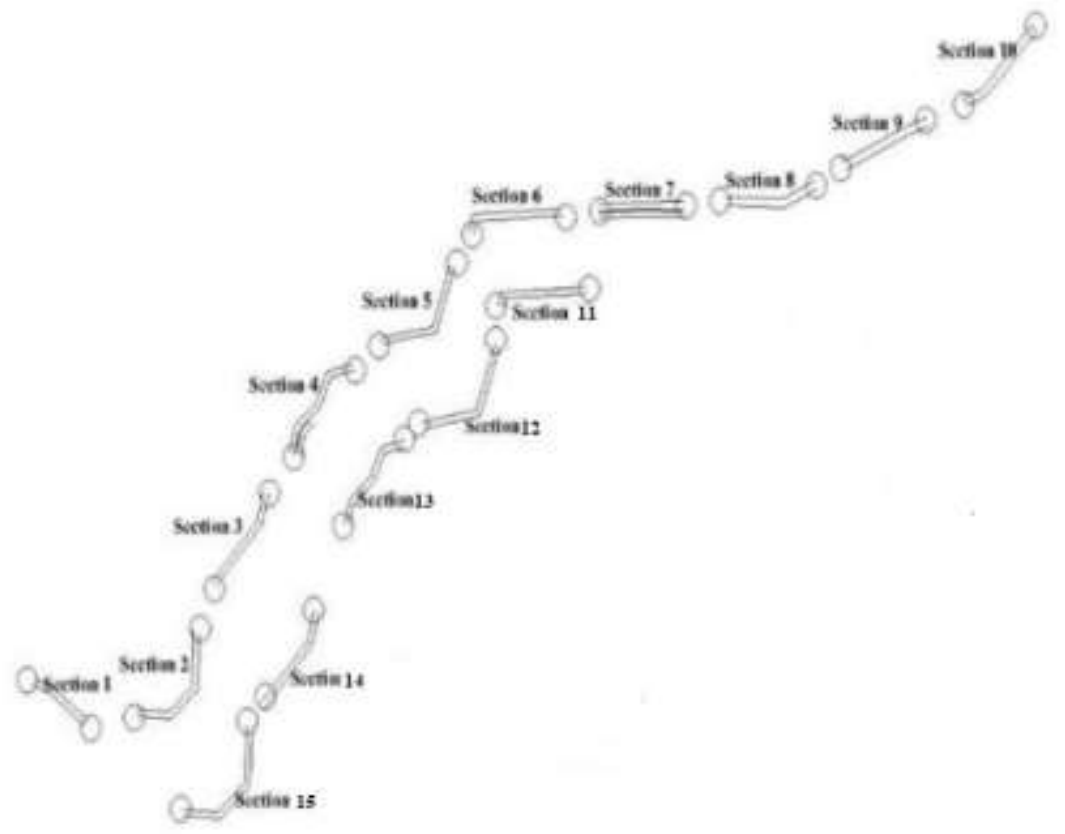

Gambar 1. Sket lokasi penelitian dan pembagian segmen

Lokalisasi penelitian ini terbagi menjadi 15 segmen dengan panjang penampang antara $700 \mathrm{~m}$ sampai dengan $1.358 \mathrm{~m}$. Penyelidikan lebih lanjut telah dilakukan pada setiap bagian yang dibagi menjadi beberapa sampel dan membuat kategori kerusakan dengan mengklasifikasikan tingkat keparahan dalam 3 level yaitu rendah (L), sedang
(M) dan tinggi $(\mathrm{H})$. Untuk setiap jenis kerusakan dan keparahan diklasifikasikan menjadi 1 variabel $\mathrm{x}$, contoh jenis kerusakan retak buaya (alligator crack) dengan level rendah (L) dinyatakan dengan $\mathrm{x} 1$, untuk retak buaya dengan level sedang $(\mathrm{M})$ dinyatakan dengan $\mathrm{x} 2$, untuk retak buaya dengan tinggi level $(\mathrm{H})$ diekspresikan dengan $\mathrm{x} 3$ dan seterusnya.

Tabel 1. Jenis kerusakan dan tingkat keparahannya

\begin{tabular}{|c|c|c|c|c|c|c|c|c|c|c|c|c|}
\hline Tkt & $\mathbf{A}$ & Bld & BC & Corr & EC & Pol & Patc & Pot & Rut & Sho & Swe & Rav \\
\hline $\mathrm{L}$ & $\mathrm{x} 1$ & $\mathrm{x} 4$ & $\mathrm{x} 7$ & -- & $\mathrm{x} 10$ & $\mathrm{x} 13$ & $\mathrm{x} 16$ & $\mathrm{x} 19$ & $\mathrm{x} 22$ & $\mathrm{x} 25$ & -- & $\mathrm{x} 28$ \\
\hline $\mathrm{M}$ & $\mathrm{x} 2$ & $\mathrm{x} 5$ & $\mathrm{x} 8$ & $\mathrm{x} 9$ & $\mathrm{x} 11$ & $\mathrm{x} 14$ & $\mathrm{x} 17$ & $\mathrm{x} 20$ & $\mathrm{x} 23$ & -- & $\mathrm{x} 26$ & $\mathrm{x} 29$ \\
\hline $\mathrm{H}$ & $\mathrm{x} 3$ & $\mathrm{x} 6$ & -- & -- & $\mathrm{x} 12$ & $\mathrm{x} 15$ & $\mathrm{x} 18$ & $\mathrm{x} 21$ & $\mathrm{x} 24$ & -- & $\mathrm{x} 27$ & $\mathrm{x} 30$ \\
\hline
\end{tabular}
ditemukan dalam penelitian ini dengan tingkat keparahan yang berbeda-beda. Jenis kerusakan yang ditinjau adalah: 1) Alligator Crack (AC); 2) Bleeding (Bld); 3) Block Crack (BC); 4) Corrugation (Corr); 5) Edge Cracking (EC); 6)
(Pot); 8) Patching (Patc); 9)Rutting (Rut); 10) Shoving (Sho); 11) Swell (Swe) dan 12) Raveling (Rav) sehingga terdapat 30 variabel $\mathrm{x} 1, \mathrm{x} 2, \mathrm{x} 3, \mathrm{x} 4, \mathrm{x} 5, \ldots$, $\mathrm{x} 30$. Semua variabel dan parameter ditunjukkan pada tabel 1 , di mana $\mathrm{L}$ 
adalah tingkat keparahan Rendah, M Tingkat Keparahan Sedang dan $\mathrm{H}$ Tingkat Keparahan Tinggi.

Dalam studi ini, data dibagi menjadi beberapa subset pelatihan dan pengujian, untuk memastikan bahwa standar deviasi dari variabel yang berbeda di setiap subset relatif sedekat mungkin. Proses trial and error digunakan untuk mencapai tujuan ini. Terakhir, $80 \%$ data dialokasikan ke subset pelatihan, dan $20 \%$ sisanya digunakan untuk pengujian.

\section{Artificial Neural Networks}

ANN atau jaringan saraf tiruan adalah struktur pemetaan nonlinier yang membentuk model matematika kompleks yang terinspirasi oleh jaringan saraf biologis. Pemodelan berbasis ANN adalah pendekatan untuk memecahkan masalah pengenalan pola dan masalah teknik data mining. Jaringan saraf tiruan terdiri dari banyak neuron buatan yang disebut elemen pemrosesan (PE) -unit atau node. Fungsi ANN sangat ditentukan oleh hubungan antara elemenelemen ini. ANN dapat dilatih untuk tampil fungsi standar tertentu dengan menyesuaikan nilai koneksi (yaitu, bobot) antar elemen. Prosedur pemodelan ANN disajikan secara grafis pada Gambar 2. Proses pemodelan ANN diilustrasikan dalam diagram alir yang ditunjukkan pada gambar 3 .

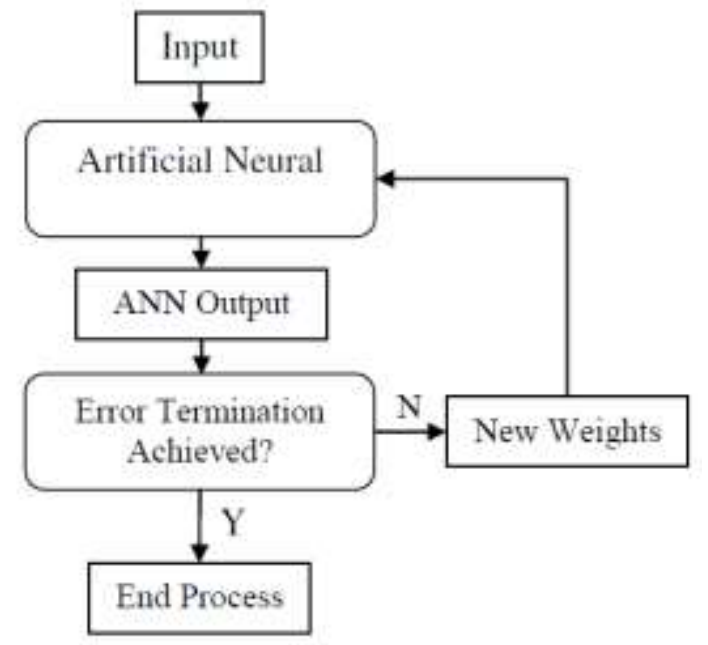

Gambar 2. Prosedur Modeling ANN

Gambar 3 menunjukkan arsitektur jaringan, arsitektur ini terdiri dari lapisan masukan, lapisan tersembunyi, dan lapisan keluaran. Lapisan keluaran memiliki satu neuron, dan lapisan tersembunyi memiliki 19 neuron.

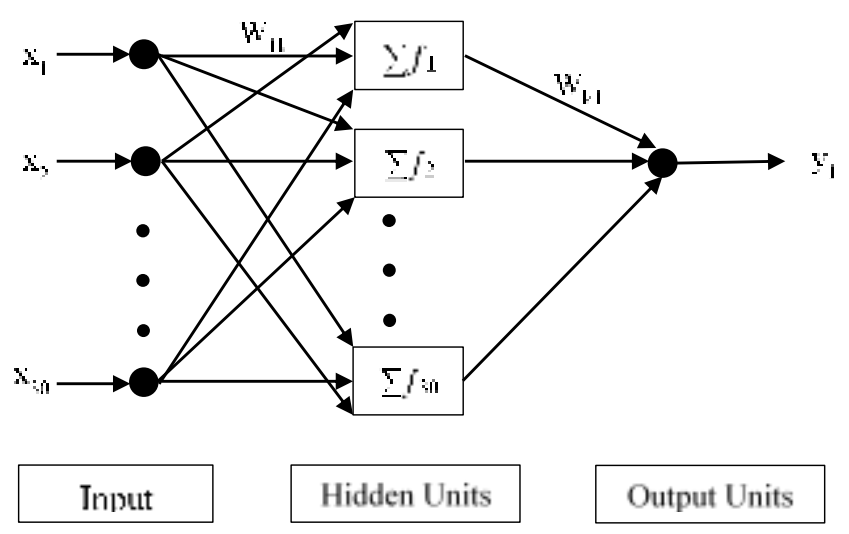

Gambar 3. Arsitektur Jaringan

\section{Pavement Condition Index}

Penelitian sebelumnya telah menjelaskan bahwa untuk mendapatkan nilai PCI maka prosedur yang harus diikuti adalah: 1) Menentukan distress perkerasan dan tingkat keparahannya, yang bisa rendah, sedang dan tinggi; 2) Menentukan nilai deduksi dari kurva nilai deduksi berdasarkan gbr. 4. menunjukkan kurva kalkulasi nilai deduksi; 3) Pengurangan nilai pengurangan dari jumlah maksimum yang diperbolehkan sesuai dengan gambar. 5; 4) Penentuan q, besarnya nilai deduksi lebih besar dari 2; 5) Penentuan nilai total deduksi (TDV) yang merupakan penjumlahan dari 
seluruh nilai deduksi; 6) Penentuan nilai deduksi terkoreksi (CDV) berdasarkan kurva koreksi menggunakan q dan TDV; 7) Pengurangan nilai deduksi terkecil lebih besar dari 2 menjadi tepat $2 ; 8$ ) Pengulangan langkah 4 sampai 7 sampai q sama dengan 1; 8) Penentuan CDV maksimum (CDVmax) dan perhitungan PCI (Shahin, 1994).

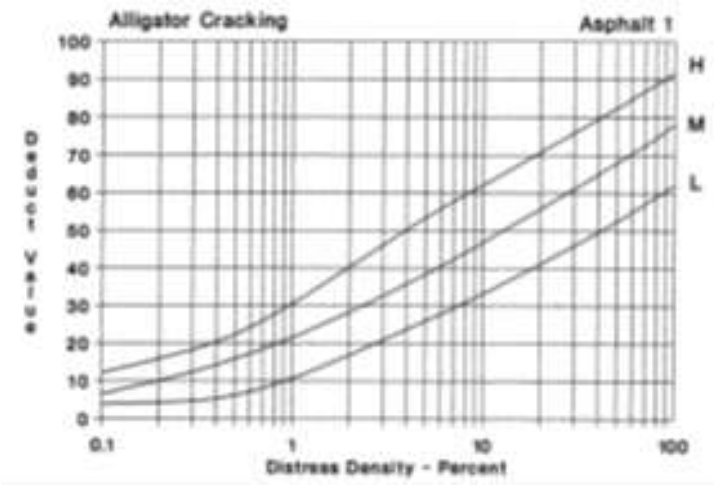

Gambar 4. Contoh grafik deduct value untuk alligator cracking.

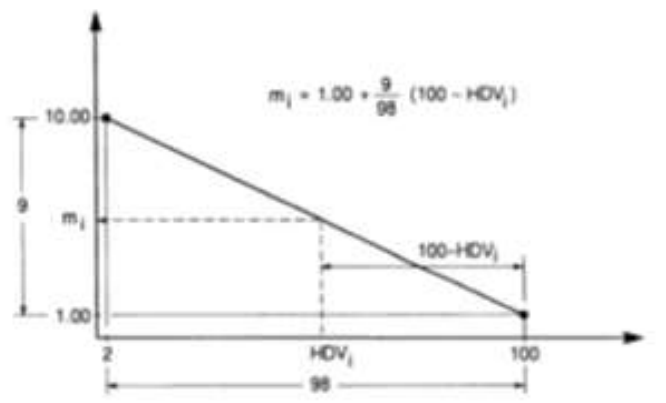

Gambar 5. Grafik penentuan deduct maksimum

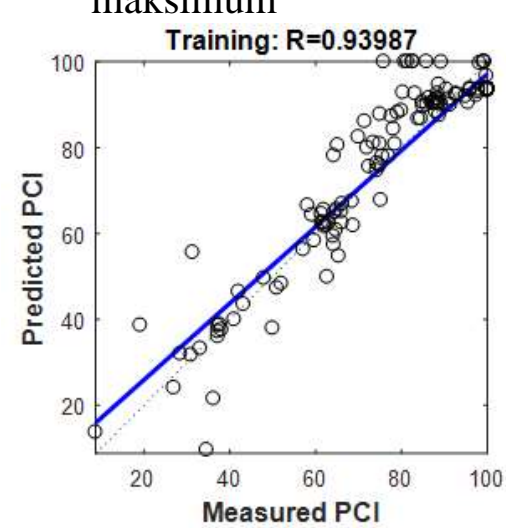

(a)

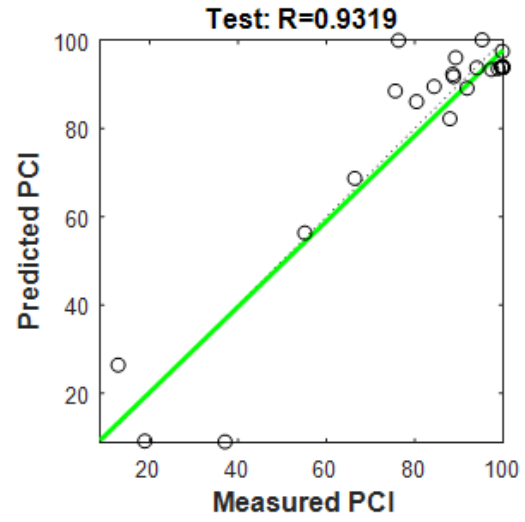

(b)

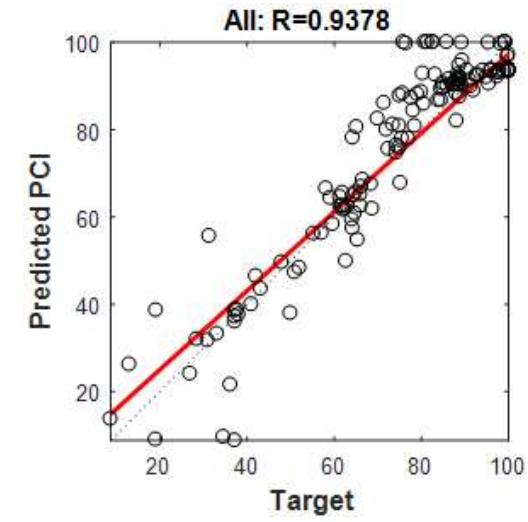

(c)

Gambar 6. PCI terukur vs prediksi PCI (a) latihan, (b) pengujian, (c) semua data

Selain kinerja model yang baik untuk subset pelatihan dan pengujian, ruas jalan yang berbeda sepanjang $15 \mathrm{~km}$ (15 ruas) digunakan untuk verifikasi
Nilai pengurangan untuk kerusakan individu ditentukan dengan memasukkan tingkat kerusakan dalam hal densiti kerusakan. Densitas kerusakan dihitung dengan mengambil area kerusakan yang diukur dan membaginya dengan total luas area unit sampel perkerasan yang diinspeksi. Dengan mencocokkan densitas distress dengan tingkat keparahan kerusakan, nilai pengurangan ditentukan dari kurva seperti yang ditunjukkan pada gambar 4 dan 5 (Lav, Goktepe, \& Lav, 2009). ASTM D643307 menetapkan skala peringkat PCI antara 0 - 10 (gagal), 11 - 25 (serius), 26 - 40 (sangat buruk), 41 - 55 (buruk), 56 70 (sedang), 71 - 85 (memuaskan), dan 86 - 100 (baik).

\section{HASIL PENELITIAN}

Kinerja model dievaluasi dalam $\mathrm{R}$ (koefisien determinasi) sebagai kontribusi pengaruh yang diberikan variabel independen $(\mathrm{x})$ terhadap variabel dependen (y). Gambar 6 menunjukkan performa akhir model berbasis ANN untuk pelatihan, pengujian, dan semua data. Performa model menunjukkan kemampuan ANN untuk pemodelan PCI. 
dari model yang diusulkan untuk set validasi.

Perbedaan penelitian ini dengan penelitian sebelumnya adalah parameter yang digunakan lebih banyak berjumlah
30 dibandingkan penelitian sebelumnya yang hanya berjumlah 21 parameter sehingga dapat merepresentasikan lebih banyak kondisi kerusakan perkerasan yang sering terjadi di wilayah Indonesia.

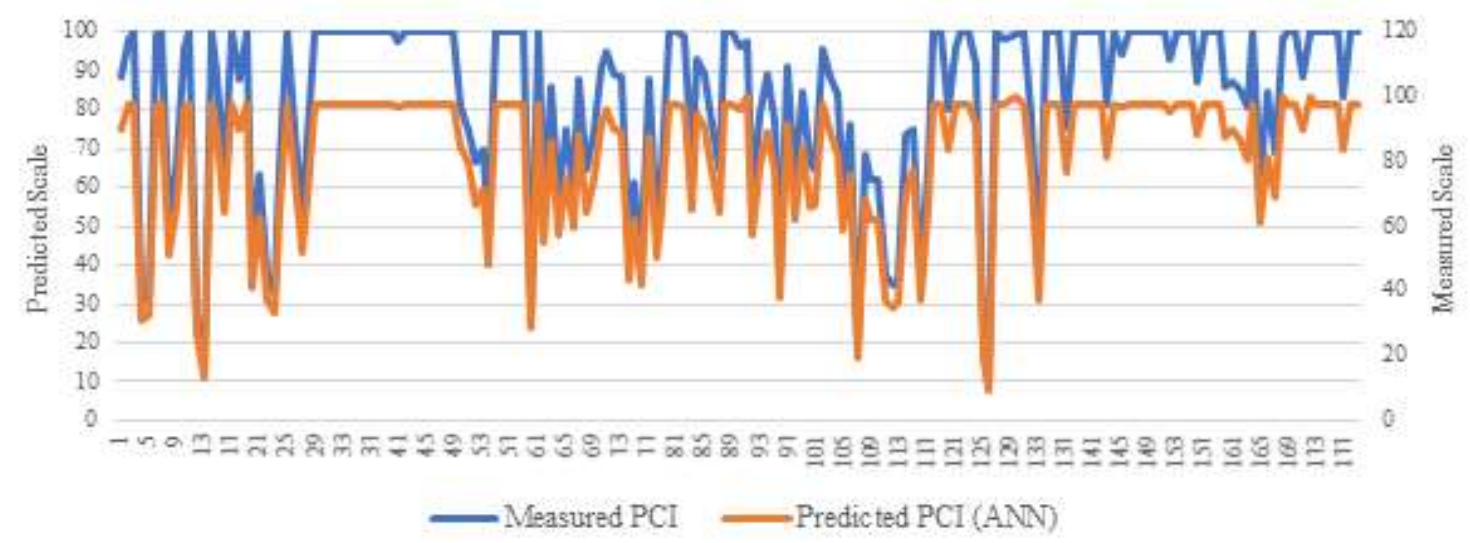

Gambar 7. Grafik validasi antara prediksi PCI dan PCI terukur

Tabel 2. Validasi antara prediksi PCI dan PCI terukur

\begin{tabular}{ccccccccc}
\hline SECTION & $\mathbf{1}$ & $\mathbf{2}$ & $\mathbf{3}$ & $\mathbf{4}$ & $\mathbf{5}$ & $\mathbf{6}$ & $\mathbf{7}$ & $\mathbf{8}$ \\
\hline PCI terukur & 78.30 & 67.35 & 66.03 & 77.38 & 100.00 & 99.76 & 74.13 & 80.19 \\
PCI prediksi & 77.76 & 66.87 & 65.70 & 75.84 & 97.71 & 97.59 & 76.79 & 78.94 \\
\hline SECTION & $\mathbf{9}$ & $\mathbf{1 0}$ & $\mathbf{1 1}$ & $\mathbf{1 9}$ & $\mathbf{1 3}$ & $\mathbf{1 4}$ & $\mathbf{1 5}$ & \\
\hline PCI terukur & 78.03 & 71.00 & 97.29 & 96.84 & 95.61 & 86.54 & 96.86 & \\
PCI prediksi & 78.14 & 70.49 & 95.34 & 95.76 & 94.72 & 85.76 & 95.48 & \\
\hline
\end{tabular}

\section{KESIMPULAN}

Penelitian ini mengembangkan perhitungan PCI dengan komputasi lunak berbasis ANN untuk menghasilkan metode perhitungan yang lebih sederhana jika dibandingkan dengan perhitungan menggunakan metode manual yang membutuhkan 8 langkah panjang dan rumit. Software untuk menghitung PCI juga telah dikembangkan yaitu Micro Paver, hanya saja tidak semua orang bisa mendapatkan software karena keterbatasan akses dan finansial. Soft computing diharapkan dapat membantu mempermudah penghitungan PCI untuk daerah/lokasi dengan karakteristik yang tidak jauh berbeda dengan objek pada penelitian ini.

Diperlukan penelitian lebih lanjut dengan menambahkan parameter yang mempengaruhi kerusakan perkerasan dan dengan data yang lebih banyak dengan cakupan jaringan jalan yang lebih luas.

\section{DAFTAR PUSTAKA}

Chen, C., \& Flintsch, G. W. (2007). Fuzzy logic pavement maintenance and rehabilitation triggering approach for probabilistic life-cycle cost analysis. Transportation research record, 1990(1), 80-91.

Hadiwardoyo, S., Sumabrata, R., \& Berawi, M. (2012). Tolerance limit for trucks with excess load in transport regulation in Indonesia. Makara Journal of Technology, 16(1), 85-92.

Huang, Y. H. (2004). Pavement analysis and design.

Kelly, G., Delaney, D., Chai, G., \& Mohamed, S. (2016). Optimising local council's return on investment from annual pavement rehabilitation budgets through targeting of the average pavement condition index. Journal of traffic and 
transportation engineering (English edition), 3(5), 465-474.

Lav, A. H., Goktepe, A. B., \& Lav, M. A. (2009). Backcalculation of flexible pavements using soft computing. In Intelligent and Soft Computing in Infrastructure Systems Engineering (pp. 67106): Springer.

Leiva-Villacorta, F., Vargas-Nordcbeck, A., \& Timm, D. H. (2017). Nondestructive evaluation of sustainable pavement technologies using artificial neural networks. International Journal of Pavement Research and Technology, 10(2), 139-147.

Lou, Z., Gunaratne, M., Lu, J., \& Dietrich, B. (2001). Application of neural network model to forecast shortterm pavement crack condition: Florida case study. Journal of Infrastructure Systems, 7(4), 166171.

Meegoda, J. N., \& Gao, S. (2014). Roughness progression model for asphalt pavements using longterm pavement performance data. Journal of Transportation Engineering, 140(8), 04014037.

Shah, Y. U., Jain, S., Tiwari, D., \& Jain, M. (2013). Development of overall pavement condition index for urban road network. Procedia-Social and Behavioral Sciences, 104(2), 332-341.

Shahin, M. (1994). Pavement Management for Airports, Roads, and Parking Lots. Chapman \& Hall, New York.

Shahnazari, H., Tutunchian, M. A., Mashayekhi, M., \& Amini, A. A. (2012). Application of soft computing for prediction of pavement condition index. Journal of Transportation Engineering, 138(12), 14951506.

Yogesh U. Shah, D. S. S. J., Dr. Devesh Tiwari and Dr.M.K. Jain. (2012).
Soft Computing Applications for Urban Pavement Maintenance Management System. Paper presented at the International Conference on Advances in Architecture and Civil Engineering (AARCV 2012). 